\title{
La imagen de la liebre en los tejidos de la Antigüedad Tardía del Valle del Nilo
}

\author{
Image of the hare in textiles of Late Antiquity from \\ Nile Valley
}

Laura RODRÍGUEZ PEINADO

Universidad Complutense de Madrid

Recibido: 24-II-2015 / Aceptado: 21-IV-2015

Resumen: La liebre es un animal telúrico que en distintas culturas ha tenido un carácter sagrado. Durante la Antigüedad Tardía fue un animal benefactor y su representación en los textiles del Valle del Nilo muestra su imagen asociada a tradiciones faraónicas, grecorromanas y cristianas, con un significado que varía en función del contexto, pero en general fue un icono con un claro carácter profiláctico y apotropaico que procuraba fertilidad, fortuna y era un claro referente de la renovación cíclica, con poder de regeneración y relacionada con la inmortalidad.

Palabras clave: Liebre, Lepus, Conejo, Iconografía animal, Decoración textil, Antigüedad Tardía.

ABSTRACT: The hare is a telluric animal in different cultures had a sacred character. During Late Antiquity was an animal of good luck. In textiles of Nile Valley its image is associated with Pharaonic, Greco-Roman and Christian traditions, with a meaning that varies depending on the context, but it was an icon with a clear prophylactic and apotropaic character, symbol of fertility and fortune. Also was a symbol to the cyclical renewal, regeneration and immortality.

Keys words: Hare, Lepus, Rabbit, Animal iconography, Textile decoration, Late Antiquity.

Los animales siempre han estado presentes en el imaginario artístico como fuente de inspiración, tanto por sus cualidades gráficas como simbólicas ${ }^{1}$. Gráficamente han sido susceptibles de representaciones naturalistas o esquemáticas donde lo formal y lo

\footnotetext{
${ }^{1}$ Este artículo está realizado en el marco del Proyecto de Investigación “Las manufacturas textiles andalusíes: caracterización y estudio interdisciplinar", HAR201454918-P, del Ministerio de Economía y Competitividad.
}

sígnico trascienden a una condición simbólica, porque los animales, como soporte didáctico, han constituido la expresión de los poderes de la naturaleza, de fuerzas sobrenaturales y de valores religiosos, así como un medio de comunicación con lo divino mediante actos rituales, de modo que aunque forman parte integral de la vida cotidiana de los hombres, el interés que han suscitado en el imaginario colectivo sobrepasa su estricta función utilitaria y se los ha dotado de cua- 
lidades o defectos más propios de los humanos en función de su carácter ${ }^{2}$, sin olvidar que también detentaron un importante valor estacional $^{3}$. Es por eso por lo que formando escenas o en solitario se han representado en diferentes soportes y técnicas, siendo necesario en todos los casos interpretar icónicamente su significado, que puede variar en función de la consideración que las distintas culturas han tenido sobre cada especie.

Si bien es cierto que las atribuciones dadas a un animal determinado a menudo trascienden los ámbitos culturales, también hay que afirmar que la misma especie puede adoptar valores positivos o negativos en función del contexto dentro del mismo entorno cultural.

\section{LA LIEBRE EN LAS CULTURAS DE LA ANTIGÜEDAD}

Los egipcios desde antiguo compartieron una relación equilibrada con los animales. Creían que los seres humanos, los animales y las plantas eran miembros de un todo único y consideraban su unión como parte esencial del orden cósmico. Cada dios del panteón egipcio se vinculó con un animal, asociándose las funciones divinas con las fuerzas de la naturaleza. Heródoto narra que perros, gatos y monos convivían con las familias como mascotas, mientras animales más exóticos como los leones se reservaban para la realeza. Según el historiador romano, todos tenían un carácter sagrado ${ }^{4}$. Por tanto, los animales fueron una fuente fundamental de la espiritualidad, el compañerismo y el sustento entre los egipcios.

${ }^{2}$ Véase sobre estos aspectos para el caso de la Edad Media, J. TOUSSAINT (dir.), Fabuleuses histoires. Des bêtes et des hommes, "Monographies du TreM.a”, nº 61, Namur, 2013.

${ }^{3}$ En este sentido, la liebre era el símbolo de la primavera, el tiempo del año en el que la naturaleza despierta de su estado letárgico invernal alegorizando, en el caso del Valle del Nilo -espacio geográfico donde se desarrollan las manifestaciones artísticas a las que se dedica este artículo-, la generosidad del río y la abundancia con que proveía a la población. En términos antropológicos, esta conexión con la primavera se mantiene en la actualidad con la tradición del conejo de Pascua.

${ }^{4}$ Heródoto, Historias, 2, LXV-LXXVI.
Entre estos estaba la liebre (lepus, de la familia de los leporidae), uno de estos animales telúricos omnipresentes en todas las civilizaciones cuya representación está dotada de valores universales y ambivalentes. Caracterizadas por sus grandes orejas puntiagudas y largas patas traseras, son muy rápidas, su carácter es tímido y asustadizo, viven escondidas en madrigueras y entre matorrales junto a sus congéneres y se distinguen por su gran agudeza sensorial y una extraña habilidad para sentir el peligro, cualidades por las que se las otorgaron una serie de significados ${ }^{5}$.

Los antiguos egipcios otorgaron a la liebre, conocida como sekhat, un carácter divino. El valor fonético de su jeroglífico -wnexpresado con el sonido "oon" o "oonen", era símbolo de la esencia de la vida e ideograma de los verbos "ser" y "existir" ${ }^{\text {. Aun- }}$ que al igual que otras criaturas del desierto se consideraba potencialmente peligrosa, por su fertilidad se le asignaron poderes de regeneración; la rapidez de sus movimientos y la agudeza de sus sentidos fueron interpretados como signo de defensa contra las fuerzas de la oscuridad y su imagen se asoció con la vigilancia, porque existía la creencia de que dormía con los ojos abiertos. Por tanto, fue dotada de un valor apotropaico y su amuleto podía conferir a su portador el don de la fertilidad, y si este era un difunto suponía la esperanza en un renacimiento.

\footnotetext{
${ }^{5}$ En este artículo nos vamos a centrar en el estudio simbólico de la liebre en el territorio egipcio durante los primeros siglos de nuestra era, por lo que veremos cuál ha sido su significado entre egipcios y pobladores de otras culturas que habitaron el territorio, como griegos, romanos y cristianos. Pero entre los pueblos europeos y asiáticos también fue un animal que gozó de importancia; así, por ejemplo, para los chinos era un signo de buen augurio y para los mongoles era un animal guía, véase J. A. BOYLE, "The hare in the myth and reality, a review article", Folklore, 84, 4, 1973, pp. 313-326; IDEM, "The owl and the hare in the popular beliefs on the medieval mongols", Central Asiatic Journal, 23, 1.2, 1979, pp. 65-71.

${ }^{6}$ R. SCHUMANN-ANTELME y S. ROSSINI, Illustrated Hieroglyphics Handbook, New York, 2002, pp. 232233; Á. SÁNCHEZ RODRÍGUEZ, Diccionario de jeroglíficos egipcios, Madrid, 2004, pp. 267-271.
} 
Las referencias a la liebre son abundantes en la mitología y la literatura egipcia. El faraón Unas -Wnis- (V dinastía, 2378-2348 a.C.) se identifica con el jeroglífico $w n$ en los Textos de las Pirámides. El nomo XV del Alto Egipto con capital en Khmunu se llamaba $W n t^{7}$. La liebre estaba asociada a las deidades del Otro Mundo ${ }^{8}$, como la diosa Iunit (Iwnit/Unnet/Unut), representada bien en forma del animal, en forma femenina con un estandarte con una liebre reclinada sobre su cabeza, o como una mujer con cabeza de lepórido. Como diosa lunar acompañaba a los muertos en su tránsito a la otra vida, función que podía desempeñar la liebre y en este contexto podía portar en la boca el hongo funerario recordando la necesidad de traspasar el umbral de la muerte de acuerdo a los mandatos divinos ${ }^{9}$. Era la mensajera del dios lunar Thoth-Dyeuthy y protectora de los difuntos, a los que ayudaba en su tránsito a las regiones de Occidente, de ahí la necesidad de que se colocaran amuletos con su imagen entre los vendajes de la momificación. Osiris a veces se representaba como Un-Nefer con cabeza de liebre, por eso el sacrificio de uno de estos animales cada año en el Nilo garantizaba la inundación anual que hacía posible la renovación de la tierra y los cultivos.

En Grecia la liebre se asoció con Artemisa, la diosa olímpica de la caza y de los animales salvajes. También se consideró el animal sagrado de Afrodita y de Eros, considerándose la ofrenda de liebres vivas un obsequio amoroso ${ }^{10}$. Hermes la colocó entre las

${ }^{7}$ Ancient Egyptian geography: Nomes, cities and sites, consultado el 5 de febrero de 2015. URL http://www. reshafim.org.il/ad/egypt/geography/cities.htm.

8 H.B. WERNESS, The Continuum encyclopedia of animal symbolism in art, New York, 2003, pp. 206-207.

9 E. CASTEL, Egipto. Signos y símbolos de lo sagrado, Madrid, 1999, pp. 228-229.

${ }^{10}$ En Roma eran las mujeres estériles las que hacían estas ofrendas como tributo para alcanzar la fertilidad. Theoi Greek Mythology. Exploring Mythology in Classical Literature $\mathcal{E}$ Art, consultado el 9 de febrero de 2015. URL http://www.theoi.com/Olympios/AphroditeTreasures. html. estrellas como la constelación Lepus ${ }^{11}$. Higinio la nombra en relación a otras figuras mitológicas como Orión ${ }^{12}$, aludiendo en este caso a su voracidad ${ }^{13}$. Por sus costumbres noctámbulas fue considerada un animal lunar, de hecho se identifica con su silueta una de las sombras que proyecta el astro, razón por la cual también se asoció a la diosa lunar Hécate, quien tiene en la liebre uno de sus atributos $^{14}$. También fue vinculada a Dionisos, el gran dios olímpico de la vegetación, los placeres y lo festivo, considerado un símbolo de renacimiento y renovación. Esta conexión estaba reforzada porque el animal destruía los viñedos y las uvas, atributos del dios, y para evitarlo sus seguidores le ofrecían liebres vivas, al igual que a Afrodita y a Eros, como muestra el ánfora del pintor Amasis conservado en el Cabinet des Medailles, Bibliothèque Nationale de France, (ca. 540-530 a.C.) donde unas ménades se la ofrecen al dios como símbolo de su amor y entrega ${ }^{15}$.

Los autores clásicos atribuyen al animal diferentes significados. Aristóteles la identifica con el deseo sexual y el amor carnall ${ }^{16}$; para Plutarco era símbolo de velocidad y vigilancia ${ }^{17}$; y de fertilidad y sexualidad apasionada para Apolonio de Tiana (3 a.C. ca. 97). Sin embargo para Claudio Aeliano ${ }^{18}$ y Horacio $^{19}$ simboliza el miedo y la cobardía ${ }^{20}$. En la Biblia se menciona como animal

\footnotetext{
11 Ibídem. URL http://www.theoi.com/Olympios/ HermesTreasures.html.

${ }^{12}$ Ibídem. URL http://www.theoi.com/Cat_Astraioi2. html.

${ }^{13}$ Higinio, De Astronomia, I, 2:33.

14 J. E. CIRLOT, Diccionario de símbolos. Madrid, 2007, p. 284.

15 Theoi Greek Mythology... URL http://www.theoi. com/Gallery/K12.28.html.

${ }^{16}$ Aristóteles, Metafísica, Libro VI, 33.

${ }^{17}$ Plutarco, Moralia, Isis y Osiris, 74, 381a.

${ }^{18}$ Claudio Aeliano, De Natura Animalium, VII, 19.

${ }^{19}$ Horacio, Odas, V, 2, v. 35.

${ }^{20} \mathrm{G}$. de TERVARENT, Atributos y símbolos en el arte profano, Madrid, 2002, pp. 336-337.
} 
impuro de acuerdo a la tradición judía. En el Levítico y el Deuteronomio se considera un animal inmundo porque aunque rumia no tiene la pezuña hendida ${ }^{21}$.

En los primeros tiempos del cristianismo se representan en relieves, epitafios, lámparas de aceite y otros objetos, y aunque su significado no está claro, en contextos funerarios son símbolo de prudencia y resurrección, así como de vigilancia por la creencia de que dormían con los ojos abiertos, como menciona Aeliano ${ }^{22}$. Pero para los cristianos, igual que para los judíos, pronto se convirtió en símbolo de libertinaje y concupiscencia por su fecundidad; así exégetas como Clemente de Alejandría tacha al animal de corruptor porque copula sin moderación ${ }^{23}$, simbolismo del que se harán eco las artes de la Edad Media ${ }^{24}$. El Physiologus menciona como singularidad que con sus patas delanteras más cortas podía correr hacia arriba eludiendo a sus perseguidores, por lo que se identificaba con todos aquellos que solo confían en Dios ${ }^{25}$. Por tanto, durante la Edad Media, en función de la representación podía tener connotaciones positivas o negativas $^{26}$.

En el siglo XVI Valeriano Bolzani recoge los distintos significados de la liebre en las culturas antiguas ${ }^{27}$.

\section{LA LIEBRE EN EL ARTE TEXTIL}

Durante la Antigüedad Tardía la liebre gozó de gran protagonismo en la decora-

${ }^{21}$ Levítico, 11, 6; Deuteronomio, 14, 7.

${ }^{22}$ Aeliano, De Natura Animalium, II, 12.

${ }^{23}$ Clemente de Alejandría, Pedagogus, 2.88.1-2.

${ }^{24}$ I. MONTEIRA ARIAS, La escultura románica y la lucha contra el Islam (mediados del siglo XI a mediados del siglo XIII), Madrid, 2010, p. 461.

${ }^{25}$ H. BIEDERMANN, Diccionario de símbolos, Barcelona, 1993, p. 269.

${ }^{26}$ L. RODRÍGUEZ PEINADO, “Los conejos y las liebres", Revista Digital de Iconografía Medieval, vol. III, nº 5, 2011, pp. 11-21.

${ }^{27}$ Valeriano Bolzani, Hieroglyphica, XIII. ción textil, pudiendo asumir un papel principal o más anecdótico, pero siempre cargado de significado. Su presencia, por tanto, es un exponente de su importancia en las diferentes culturas de la cuenca del Mediterráneo.

Las características del clima y suelo egipcios han favorecido la conservación de un importante volumen de piezas textiles de los primeros siglos de nuestra era procedentes de los enterramientos del Valle del Nilo. La ocupación romana en Egipto dio lugar a una transformación de los hábitos milenarios de enterramiento al abandonarse el ritual de la momificación. Los difuntos pasaron a enterrarse en un ataúd de madera vestidos con sus mejores ropas y envueltos en un sudario ${ }^{28}$ y la ubicación de las necrópolis en los márgenes del desierto, en tumbas practicadas en la arena a poca profundidad, ha favorecido la conservación de los tejidos que componían los ajuares funerarios por la sequedad del clima. Estos ajuares son de un inestimable valor porque permiten conocer la industria textil de la Antigüedad Tardía en los territorios orientales del Imperio, ya que por su carácter orgánico su conservación en otros emplazamientos ha sido muy fragmentaria ${ }^{29}$. También ayudan a entender el repertorio utilizado por los tejedores, caracterizado por una mezcla de tradiciones.

Los tejidos conservados forman parte de túnicas, mantos, chales, velos y otras prendas de la indumentaria, además de grandes piezas como manteles, colchas o cortinas utilizados como sudario. Estas telas se decoraban con clavi, orbiculi, tabulae y motivos en

${ }_{28}$ M.-H. RUTSCHOWSCAYA y D. BÉNAZETH (dirs.), L'art copte en Égypte. 2000 ans de christianisme, Catálogo de la exposición, París, 2000, pp. 105-106.

${ }^{29}$ Fuera de Egipto destacan los hallazgos en Palmira y Dura Europos: R. PFISTER, Textiles de Palmyre, París, 1934; ÍDEM, Nouveaux textiles de Palmyre, París, 1937; ÍDEM, Textiles de Palmyre III, París, 1940; R. PFISTER y L. BELLINGER, Excavations at Dura-Europos. Report IV, part II: the Textiles, New Haven, 1945. Para los hallazgos en emplazamientos egipcios, véase como síntesis $\mathrm{S}$. SCHRENK (ed.), Textiles in situ. Their find spots in Egypt and neighbouring countries in the first millennium $C E$, "Riggisberger Berichte", no 13, Riggisberg, 2006. 
semillero, estos últimos sobre todo en las de gran formato; y entre los temas que conformaban su decoración se aprecian distintas influencias que provienen de la diversidad de grupos étnico-religiosos que transitaron y poblaron el territorio, porque durante el primer milenio d.C. se produjeron en Egipto profundos cambios que impactaron en la forma de vida y en las costumbres religiosas de su población al ser ocupado por griegos, romanos, persas y bizantinos, de los que asimilaron muchas de sus tradiciones.

La conquista de Alejandro Magno el 323 a.C. marcó el comienzo de un proceso de síntesis que afectó a la cultura, el lenguaje y la religión. Su civilización milenaria cautivó a sus conquistadores, quienes adoptaron muchas tradiciones y rituales del pueblo egipcio y, a su vez, las tradiciones de los habitantes del Valle del Nilo también se alteraron. Se modificó su lenguaje y adoptaron las deidades del panteón griego primero $\mathrm{y}$ romano después, cuando Egipto fue anexionado al Imperio tras la batalla de Actium en el año 31 d.C. Estos cambios se revelaron con mayor intensidad cuando el cristianismo comenzó a transformar las costumbres religiosas de sus habitantes ${ }^{30}$, periodo coincidente con la dominación bizantina primero y sasánida después.

La influencia artística y cultural bizantina y sasánida estuvieron presentes hasta que tras la conquista árabe se comenzó a fraguar una transformación más radical impuesta por la nueva cultura y premisas estéticas marcadas por la forma de vida islámica.

${ }^{30}$ P. du BOURGUET, Les coptes, París, 1988, pp. 2335. Véase, asimismo, S.P. ELLIS, Graeco-Roman Egypt, Haverfordwest, 1992. De acuerdo a la tradición, el cristianismo se introdujo en Egipto por medio de San Marcos, que llegó a Alejandría el año 40 d.C. En el siglo II ya había una importante comunidad que coexistía con los devotos a cultos orientales a deidades como Dionisos, Orfeo y Serapis, identificado a menudo como Osiris. Todas estas religiones se asociaban a ritos mistéricos asimilados por el cristianismo: B. WATTERSON, Coptic Egypt, Edimburgo, 1988, pp. 1-32; C. CANNUYER, L'Egypte copte. Les chrétiens du Nil, Paris, 2000, pp. 11-28.
Por tanto, estos tejidos, conocidos en la historiografía como coptos con independencia del origen de sus tejedores y de que la temática que desarrollan sea o no cristiana $^{31}$, proporcionan una valiosa información sobre la producción textil de la Antigüedad Tardía en la cuenca del Mediterráneo, donde los diferentes centros textiles se caracterizaron por el uso de diseños y técnicas similares pero diferenciadas por el método de ejecución propio y particular de cada taller ${ }^{32}$.

Abundan los tafetanes de lino con motivos ornamentales en tapicería con tramas de lana, fibra que por su composición admitía mejor los tintes que aportaban cromatismo a estos tejidos. Pero también se practicaron otras técnicas textiles ${ }^{33}$. Su datación es problemática, porque la mayoría provienen del comercio del arte o de campañas arqueológicas de finales del siglo XIX y comienzos del siglo $\mathrm{XX}$ donde primaba el interés por obtener estas bellas piezas, lo que motivó su fragmentación y descontextualización. Es por esto por lo que para establecer un marco cronológico se hace imprescindible el análisis de las materias primas -fibras textiles y colorantes- ${ }^{34}$, las técnicas textiles y la datación por radiocarbono ${ }^{35}$.

\footnotetext{
${ }^{31}$ Aunque a partir de la conquista islámica del territorio egipcio se identifica copto con cristiano, para el periodo que nos ocupa sirve para nombrar a la población egipcia, independientemente de sus creencias y prácticas religiosas: P. du BOURGUET, Op. cit., pp. 5-12.

${ }^{32}$ M.-H. SANTROT (coord.), Au fil du Nil. Couleurs de l'Égypte Chrétienne, Catálogo de la exposición, París, 2001, pp. 30-32 y p.41, se señalan diferencias entre talleres egipcios en cuanto a sistemas de producción.

${ }^{33}$ D. de JONGHE y C. VERHECKEN-LAMMENS, "Technological discussion", en A de MOOR (ed.), Coptic Textiles from Flemish private collections, Zottegem, 1993, pp. 32-41 y Glosario, pp. 75-81.

${ }^{34} \mathrm{~J}$. WOUTERS, "Dye analysis of coptic textiles" en A. de MOOR (ed.), Op. cit., pp. 53-64.

${ }^{35} \mathrm{~A}$. de MOOR, “Radiocarbon dating of ancient textiles. State of research", en A. de MOOR y C. FLUCK (eds.), Methods of dating ancient textiles of the $1^{\text {st }}$ millennium $A D$ from Egypt and neighbouring countries, Tielt, 2007, pp. 98-111.
} 
Los tejedores tenían a su disposición un vasto repositorio de imágenes que circulaban en forma de cartones, algunos de los cuales han llegado hasta nuestros días ${ }^{36}$. Utilizaron un repertorio de tradición grecoromana, como escenas mitológicas, motivos vegetales naturalistas formando roleos, o composiciones geométricas. De tradición egipcia son animales como la rana, la langosta o la liebre a la que se dedica este estudio, vegetación propia del Valle del Nilo y escenas nilóticas con una flora y fauna propia del río donde se entrelazan la tradición egipcia y greco-romana. Más tarde se incorporaron motivos y composiciones orientalizantes de influencia sasánida y una iconografía cristiana dentro de la tradición bizantina ${ }^{37}$.

La temática animal está presente en un porcentaje elevado de tejidos, ya sea formando el motivo principal o como complemento de las escenas. Animales terrestres, acuáticos y aéreos pueblan las composiciones mostrando la variedad de la fauna del Valle del Nilo: perros, leones, panteras, carneros, cabras, ciervos, caballos, liebres, peces variados de los que surcaban las caudalosas aguas del río ${ }^{38}$ y ranas que poblaban sus charcas y riberas en época de crecida ${ }^{39}$,

${ }^{36}$ A. STAUFFER, "Cartoons for Weavers from Graeco-Roman Egypt", en D.M. BAILEY (ed.), Archaeological Research in Roman Egypt, Michigan, 1996, pp. 223-229.

${ }^{37}$ M.-H. RUTSCHOWSCAYA, Tissus coptes, Paris, 1990, pp. 77-146.

${ }^{38}$ En el conocido tapiz de los peces del Musée Historique des Tissus en Lyon se pueden distinguir varias especies (Ibídem, p. 68).

${ }^{39}$ La rana estaba relacionada con la crecida del Nilo y su abundancia. Era la personificación de la diosa Heket, garante de protección y fertilidad y ayudante del difunto durante el paso a la otra vida, aunque el exceso de estos animales podían conllevar plagas dañinas como la segunda que se narra en el Éxodo $(8,1-3)$ como castigo de Yavé al pueblo egipcio durante el cautiverio del pueblo de Israel. Véase su representación muy esquemática en una tabula del actual Museu del Diseny de Barcelona (MTIB27875): A. CABRERA LAFUENTE, “La colección de tejidos egipcios de la Antigüedad Tardía y Edad Media del Museu Téxtil y d'Indumentaria de Barcelona", en L. RODRÍGUEZ PEINADO y A. CABRERA LAFUENTE (eds.), La investigación textil y los nuevos mé- junto a otros animales marinos más exóticos como delfines y ballenas, patos, pavos, alguna gallinácea y distintas clases de aves, insectos como las langostas que producían devastadoras plagas ${ }^{40}, \mathrm{y}$ seres fantásticos y mitológicos como monstruos marinos, centauros, quimeras, caballos alados, etc. Entre todos, la liebre formó parte de decoraciones de tejidos con temática de lo más diversa que suponía, a su vez, una variación en su significado. Este también dependía de la función del tejido del que formaba parte, pero, en todo caso, no era ajeno a las atribuciones del animal en las culturas faraónica, grecorromana y cristiana como evidencia del carácter sincrético de la conocida como cultura copta $^{41}$.

La liebre se representa en los tejidos recostada sobre sus cuatro patas, apoyada sobre sus patas traseras mientras se yergue $y$ alza las delanteras, o lanzada en veloz carrera al galope minoico ${ }^{42}$. Puede ser el motivo principal de la decoración, formar parte de diferentes escenas, como las de caza, o alternar entre roleos con otros animales.

Un tipo lo forman las representaciones donde la liebre asoma entre parras y racimos. La viña fue un cultivo muy importan-

todos de estudio, Madrid, 2014, fig. 7a, p. 147. En línea: http://www.flg.es/images/publicaciones/investigaciontextil-nuevos-metodos.pdf.

${ }^{40}$ Según el Éxodo $(10,12-15)$ es la octava plaga con la que castiga el dios de los israelitas al pueblo egipcio durante su cautiverio. Véase su representación muy esquemática en un fragmento de manga de túnica del Centre de Documentació i Museu Tèxtil de Tarrasa: E. MORRAL I ROMEU (coord.), Egipte. Entre el sol y la mitja lluna, Catálogo de la exposición, Barcelona, 1999, $n^{\circ}$ reg. 18, p. 220. También se representa en una tabula del Museu del Diseny de Barcelona (MTIB32870); agradezco a Ana Cabrera la aportación de este dato.

${ }^{41}$ Es difícil diferenciar en la decoración textil entre liebres y conejos por su similar morfología, por lo que identificaremos a todos los lepóridos representados como liebres, ya que, por otra parte, eran más características de Egipto.

${ }^{42}$ En los tejidos se reconoce al animal por sus largas orejas puntiagudas, diferenciándose de otros cuadrúpedos de largas orejas redondeadas como hienas -con motas en la piel- o perros. 
te en Egipto desde la época faraónica al que se asignó un valor místico como un símbolo de regeneración. Estaba dedicada a Osiris, dios agrario cuya relación con el vino aludía a la continuidad que garantizaba el ciclo de la vida. Por su parte, la vid también era el principal atributo de Dionisos, que irrumpió en el panteón egipcio asumiendo muchos de los ritos consagrados a Osiris ${ }^{43}$. $Y$ en un contexto cristiano representa a Cristo, y sus frutos a su sangre, como deja manifiesto el pasaje del Evangelio de San Juan $(15,5)$ "Yo soy la vid; vosotros los sarmientos. El que permanece en mí y yo en él, ese dará mucho fruto; porque separados de mí nada podéis hacer".

El culto a Dionisos estaba muy extendido en Egipto, donde se había fusionado con los mitos de Osiris e Isis. Su propagación fue significativa incluso cuando el cristianismo fue ganando adeptos y se convirtió en la principal religión. Dionisos compartía importantes paralelismos con Cristo $^{44}$; ambos nacieron de madres mortales, sus seguidores celebraban ritos mistéricos donde el vino era el vehículo para la comunión con el dios y tenían esperanza en la resurrección ${ }^{45}$. Por tanto, es complicado asignar un único significado a este tema, porque si bien en ámbitos cristianos su sentido eucarístico es claro y la liebre mordisqueando un racimo y rodeada de vegetación representaría las almas del paraíso disfrutando de los frutos de la vida eterna, en un contexto dionisiaco podrían asumir similar simbolismo, ya que hemos visto como la liebre se consagra al dios para evitar que esta acabe con los frutos de la vid, razón por la que se le ofrecían liebres vivas.

En una tabula del Brooklyn Museum de Nueva York fechada en los siglos IV-V,

${ }^{43}$ L. RODRÍGUEZ PEINADO, Dioniso y lo dionisíaco en los tejidos del Valle del Nilo, Madrid, 2009, pp. 5-7. En línea: www.liceus.com.

${ }^{44}$ R.T. SHORROCK, The myth of paganism. Nonnus, Dionysus and the World of Late Antiquity, Londres, 2011, pp. 16-18.

${ }^{45}$ L. RODRÍGUEZ PEINADO, Dioniso y lo dionisíaco..., pp. 5-7. el cuadrón central está ocupado por un espécimen recostado sobre sus cuatro patas. El animal y los roleos vegetales que forman la orla se ejecutan en color púrpura, por lo que la parra con frutos rojos que rellena el campo donde está el lepórido aporta un sugestivo toque de color (Fig. 1). Al no haber ningún elemento distintivo es difícil asignar un significado concreto a esta imagen, pero independientemente de su vinculación con el dios pagano o cristiano, parece probable que se trate de una representación paradisiaca donde disfrutar de los frutos de la vida eterna, idea afín a los adeptos de ambos cultos. Las dimensiones de la tabula $(21 \times 21 \mathrm{~cm})$ permiten pensar que estuviera integrada en un tejido de ornamentación utilizado después de su uso primario con fines funerarios, adaptándose perfectamente en esta última función a las creencias en el animal que alegorizaba la renovación cíclica de la naturaleza, el renacimiento y la resurrección, ideas muy familiares a los egipcios desde la época faraónica. La liebre era el ser bueno que acompañaba al difunto y le protegía en las regiones de Occidente, por lo que su presencia en el ajuar funerario sería muy apreciada, como lo había sido desde la época faraónica ${ }^{46}$, sobre todo cuando adquiría un papel protagonista, como en este caso ${ }^{47}$.

\footnotetext{
${ }^{46}$ Como se ha comentado, en la época faraónica se ponían amuletos con la imagen de la liebre entre las vendas de la momificación para asegurar al difunto un buen viaje a la Otra Vida.

${ }^{47}$ Hay que tener en cuenta que la decoración textil en general no respondía a criterios estéticos, sino que sus motivos se elegían acorde al grupo que los demandaba y respondían a sus intereses socio-religiosos, y a este respecto hay que considerar que la pertenencia a un grupo comportaba asumir las mismas prácticas religiosas sin considerar los intereses individuales. Pero en una sociedad donde, a pesar de que tras el Edicto de Tesalónica (380) el cristianismo era la religión oficial del Imperio, la pujanza que durante la Antigüedad Tardía tuvieron las religiones paganas permitió que muchas imágenes se interpretaran con un carácter polisémico, máxime cuando su significado era cercano en las distintas creencias. Además el valor de los tejidos y el mercado de segunda mano que estos generaron inclinan a pensar que muchos de estos temas, como el de la liebre, familiares a los pobladores del territorio, tenían un sig-
} 


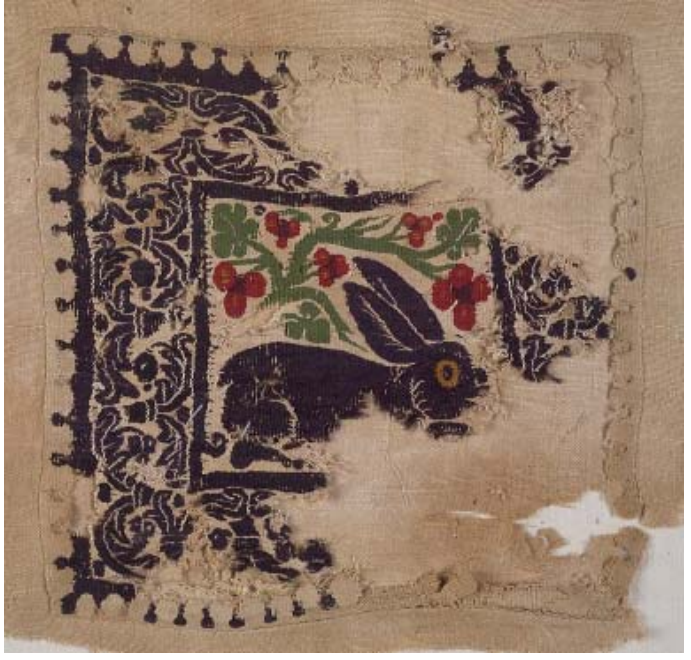

- Fig. 1. Tabulae, Brooklyn Museum, Nueva York, Inv. 42.438.2. Foto: http://www.brooklynmuseum.org/opencollection/objects/54441/ Textile_of_Purple_Hare_in_Foliage/set/a8f dc94ac6d4be7c1a06173ae26a996b?referring$\mathrm{q}=$ coptic+textiles

En una tabula del Musée Historique des Tissus de Lyon datada en el siglo VI la liebre mordisquea un racimo de uvas apoyada sobre sus patas traseras ${ }^{48}$. Es un tejido polícromo con un animal muy naturalista y en este caso tampoco hay ningún elemento que desvele su simbolismo, por lo que aunque probablemente responde a un significado similar al caso anteriormente descrito, por la avidez con que mordisquea los frutos, ¿podría sugerir ese temor al animal por parte de los seguidores de Dionisos porque devoraba los frutos dedicados al dios?; si fuese así habría que entender la consagración de la imagen animal al dios como ofrenda para proteger las viñas, pero, en todo caso, en contextos funerarios greco-romanos, estas representaciones aludían a la transformación del ciclo de la vida, la muerte y el renacimiento.

nificado polivalente comprendido por la mayor parte de la población, por lo que prendas con estos repertorios podían ser adquiridos y llevados por un amplio sector que no desdeñaban motivos que, al menos, les eran familiares.

${ }^{48}$ M.-H. RUTSCHOWSCAYA, Op. cit., Inv. 24409, p. 16.

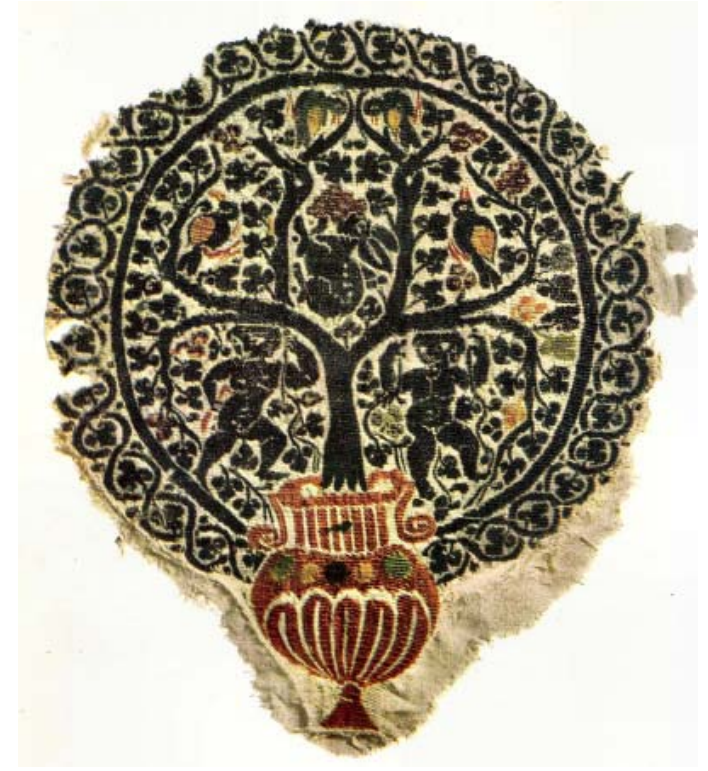

- Fig. 2. Árbol habitado, Museo de Artes Decorativas, Praga, Inv. 1214. Foto: https://www.pinterest.com/pin/541980136377504357/

La liebre también puede saborear un racimo en una frondosa vid que brota de un vaso con aves en sus ramas, como en el tejido del Brooklyn Museum fechado en los siglos IV-V ${ }^{49}$. En un tejido similar del Museo de Artes Decorativas de Praga la escena se completa con unos amorcillos vendimiadores (Fig. 2). Estas composiciones hacen alusión a los roleos habitados, con un claro significado de regeneración, donde la forma arbórea es a su vez un referente del árbol de la vida, árbol sagrado como metáfora del orden divino entre la vida y la muerte $e^{50}$. Annemarie Stauffer considera que la presencia de la liebre en un árbol de la vida hace referencia a la fertilidad y a la vida en un sentido genérico ${ }^{51}$.

En una tabula del Museo Nacional de Cerámica y Artes Suntuarias “González Martí" de Valencia las hojas de parra ocupan

${ }^{49}$ Brooklyn Museum, consultado el 9 de febrero de 2015. URL http://www.brooklynmuseum.org/opencollection/objects/54440/Textile_of_Vine_Growing_in_ Urn, Inv. 42.438.1.

${ }^{50}$ R. COOK, The Tree of Life: Image for the Cosmos, Londres, 1978.

51 A. STAUFFER, Textilien aus Ägypten - Textiles d'Egypte, Friburgo, 1991, cat. 35, p. 114. 
el cuadrón central y cuatro pequeñas liebres se disponen en el centro de cada lado. La decoración tiene un marcado carácter funerario de tradición osiriaca y dionisiaca, pudiéndose justificar la presencia de los lepóridos, que se muestran en movimiento, por su tradición como acompañantes del difunto en el viaje al Más Allá52.

Los roleos habitados constituyeron uno de los modelos compositivos más característicos de la Antigüedad Tardía, tanto en mosaicos como en escultura decorativa y otros medios artísticos ${ }^{53}$. Como una alegoría de la buena vida, su origen parece estar en el Oriente helenístico y romano. Junto a las liebres, otros animales que habitaban estos roleos eran aves, leones, panteras, hienas, perros y ciervos, todos ellos relacionados con cultos mistéricos y esotéricos, por lo que parece que complementarían el significado de las escenas figurativas que compartían. Los roleos más naturalistas se trazan como volutas sinuosas, pero en su simplificación se transforman en medallones tangentes, más habituales en los tejidos ${ }^{54}$. En Egipto se hicieron muy populares

${ }^{52}$ L. RODRÍGUEZ PEINADO y A. CABRERA LAFUENTE, "La colección de tejidos coptos del Museo Nacional de Cerámica y Artes Suntuarias “González Martí" de Valencia", Anales de Historia del Arte, 18, 2008, fig. 2, Inv. 1708, pp. 56-58.

${ }^{53}$ Los roleos habitados consisten en tallos sinuosos que pueden entrelazarse formando medallones en los que se incluyen animales, figuras humanas y motivos vegetales, pudiendo acomodarse a distintas composiciones, ya lineales u ocupando todo el campo decorativo. Sobre sus tipologías, significados y medios artísticos donde se representan véase: J.M.C. TOYNBEE y J.B. WARD-PERKINS, "Peopled Scrolls: A Hellenistic Motif in Imperial Art", Papers of the British School of Archaeology at Rome, 18, 1950, pp. 1-43; C. DAUPHIN, "Symbolic or Decorative? The Inhabited Scroll as a Means of Studying Some Early Byzantine Mentalities", Byzantium, $\mathrm{n}^{\mathrm{o}}$ 48, 1978, pp. 10-34; ÍDEM., "The Development of the "Inhabited Scroll" in Architectural Sculpture and Mosaic Art from Late Imperial Times to the Seventh Century A.D.", Levant, nำ19, 1987, pp.183-197; por su parte R. HACHLILI, Mosaic pavements. Themes, Issues and Trends, Leiden, 2008, pp. 111-147, dedica un capítulo a los roleos habitados y sus tipologías.

${ }^{54}$ Véase E. MORRAL I ROMEU, Op. cit., $\mathrm{n}^{\mathrm{o}}$ reg. 241, p. 148. En estos roleos, que conforman la decoración de a partir de los trabajos de Ahnas-el-Medineh (El Fayum $)^{55}$. Parece que podían actuar como sustitutos del paisaje egipcio, la fuente de toda la riqueza del país, razón por la que la decoración de estas composiciones se puede completar con pequeños motivos estilizados que aluden a la vegetación nilótica.

Como se ha dicho, en estos roleos la liebre puede alternar con otros animales y motivos vegetales. Las composiciones más características eran las bandas o clavi, o las orlas de los textiles en los que el tema central está relacionado con figuras alegóricas, mitológicas o una escena de caza. Del primer tipo sirva como ejemplo un fragmento de clavus del Museum Kunst Palast de Düsseldorf, donde además de dos figuras que sostienen cestos repletos de frutos, distintos animales, entre los que se distingue una liebre, se incluyen en roleos y se dirigen hacia el centro de la composición ocupado por una cruz griega potenzada inscrita ${ }^{56}$, símbolo que otorga connotaciones cristianas a la decoración con un significado positivo de resurrección y buena suerte, como fue habitual en contextos cristianos de los primeros siglos (Fig. 3). En un fragmento de gammulae del Museu d'Història de Sabadell en los roleos, que se organizan como círculos tangentes, alternan liebres y hienas junto a arquitecturas dispuestas en un esquema cruciforme, composición que se ha interpretado en otro lugar con un carácter funerario porque la liebre, como ser que conducía a los muertos al inframundo, se combina con la hiena, que en su astucia guarda el camino al paraíso, insinuado en esa arquitectura cruciforme ${ }^{57}$.

una manga, las liebres alternan con panteras y hojas de parra muy estilizadas, lo que otorga a la decoración un claro simbolismo dionisiaco.

${ }^{55}$ L. TÖRÖK, Transfigurations of Hellenism. Aspects of Late Antique Art in Egypt, AD 250-700, Leiden-Boston, 2005, figs. $47,56-58,82,84$.

${ }^{56}$ K.-H. BRUNE, Die koptischen Textilien im museum kunst palast Düsseldorf. Teil1: Wirkereien mit figürlichen Motiven, Weisbaden, 2004, cat.18, p. 58.

${ }^{57}$ L. RODRÍGUEZ PEINADO, “La decoración en los tejidos coptos. Colección del Museu d'Història de Saba- 


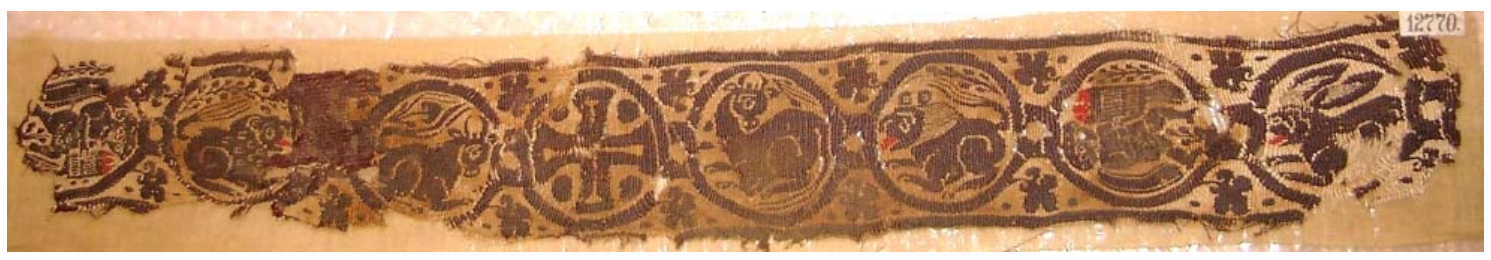

- Fig. 3. Clavus, Museum Kunst Paslast, Düsseldorf, Inv. 12770. Foto: K.-H. BRUNE, Die koptischen Textilien im museum kunst palast Düsseldorf. Teil1: Wirkereien mit figürlichen Motiven, Weisbaden, 2004, CD, cat.18

Como animal benefactor se representa completando la decoración de tejidos con escenas mitológicas, como en una túnica del Musée du Louvre con roleos en las bandas y orlas donde alternan liebres al galope minoico, leones, cabras y otros cuadrúpedos ${ }^{58}$; en la espectacular banda de la Abbeg-Stiftung de Riggisberg (Berna) ${ }^{59}$, donde, junto a otros animales, conforma la orla que rodea a una serie de escena incluidas en medallones cuadrados y circulares; o en un fragmento de clavus del Museum Kunst Paslast de Düsseldorf, con una cabra y una liebre entre figuras femeninas aladas -algunas tocando instrumentos musicales- y un bello cetáceo centrando la composición ${ }^{60}$, imágenes benefactoras en la sociedad tardoantigua.

Entre las composiciones del segundo tipo mencionamos una tabula con motivos polícromos del Museo Nacional de Artes Decorativas de Madrid ${ }^{61}$ decorada en el medallón central con un amorcillo que sujeta un recipiente y alrededor, entre roleos, alternando cestos con frutos y animales entre los que se distingue una liebre que se dirige

dell", Antiquaria, 116, 1994, fig. 13, pp. 55-56.

${ }^{58}$ M.-H. SANTROT, Op. cit., cat. 77, pp. 112-113.

${ }^{59}$ S. SCHRENK, Textilien des Mittelmeerraumes aus spätantiker bis frühislamischer Zeit, Riggisberg, 2004, cat. 22, pp. 93-96.

${ }^{60}$ K.-H. BRUNE, Op. cit., cat. 85, pp. 140-141.

${ }^{61}$ L. RODRÍGUEZ PEINADO, "Tejidos coptos del Museo Nacional de Artes Decorativas de Madrid. I", Anales de Historia del Arte, 11, 2001, cat. 18, p. 32. Similar composición tiene una tabula de la Abegg-Stiftung: S. SCHRENK, Textilien des Mittelmeerraumes..., cat. 43, p. 133. hacia una de las cestas, símbolo de fertilidad (Fig. 4). Es claramente un tema nilótico donde todos los motivos redundan en un sentido regenerador vinculados al Nilo como fuente de vida.

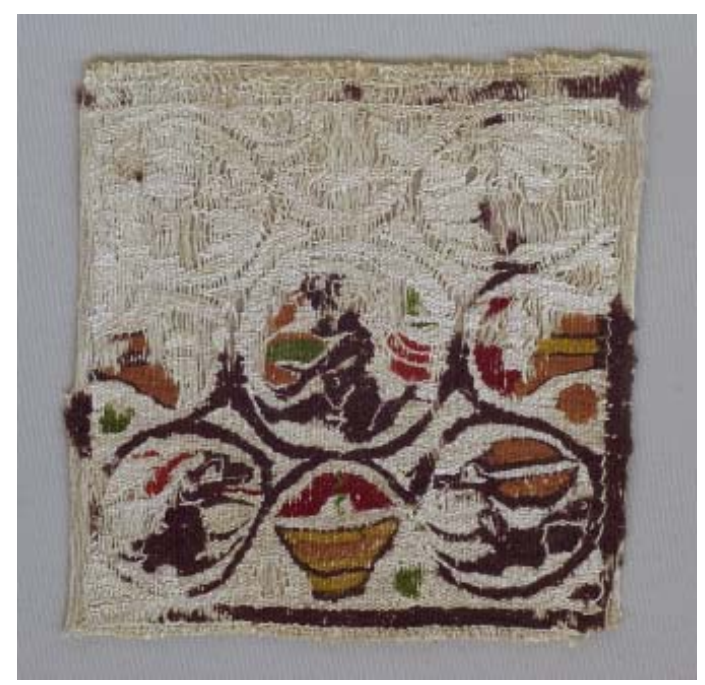

- Fig. 4. Tabula, Museo Nacional de Artes Decorativas, Madrid, Inv. Inv. 13902. Foto: Masú del Amo

En la tabula policroma del Musée des Tissus de Lyon de los siglos V-VI con un águila en el medallón central adornada con una cruz que pende de una cadena y sujetando un ankh con el pico, el ave está rodeado por un borde con volutas donde alternan liebres, leones, gacelas y cestas repletas de vegetación ${ }^{62}$. El águila encarna el papel de portador de almas y los animales de la bordura, entre los que incluye la liebre, enfatizan este significado aludiendo a la regeneración. También alternan liebres entre árboles simétricos incluidos en roleos en una tabula del Brooklyn Museum con de-

\footnotetext{
${ }^{62}$ M.-H. SANTROT, Op. cit., Inv. 24419, pp. 129-130, parece que esta tabula por su temática cristiana pudiera formar parte de un tejido litúrgico.
} 
coración en color púrpura con un cazador en actitud danzante en el cuadrón central como acto propiciatorio para obtener una abundantes caza ${ }^{63}$. Los motivos florales, además de crear un ritmo decorativo, señalan un camino alegórico hacia la eternidad.

La liebre era una de las presas más apreciada en la Antigüedad, como se muestra en las cacerías tan típicas de la decoración de mosaicos $^{64}$, razón por la cual, junto a leones, panteras, gacelas, etc., también forma parte de las escenas de caza en la decoración textil.

La caza era una evocación de la fuerza humana victoriosa sobre el mundo animal, lo que en contextos funerarios se transformaba en una lucha contra las fuerzas del mal acorde a la idea de la virtus o victoria sobre la muerte. Constituía una manera de dominar la naturaleza y su preparación implicaba una ceremonia ritual en la que se practicaban danzas propiciatorias como una manera de atraer a las presas, por eso en muchas representaciones artísticas los cazadores ejecutan pasos de danza equipados con sus armas en paisajes con abundantes animales, entre los que están las liebres, como podemos observar en una pechera de túnica del Museum Kunst Palast de Düsseldorf ${ }^{65}$, donde los cazadores evolucionan en la práctica de una danza ritual y las liebres, en círculos, emprenden una veloz carrera (Fig. 5); en un tejido del Museo Nacional de Artes Decorativas de Madrid, donde los cazadores danzantes y los animales se distribuyen en compartimentos que conforman una composición reticulada ${ }^{66} \mathrm{y}$ en la pechera de túnica

${ }_{63}$ Brooklyn Museum, consultado el 9 de febrero de 2015. URL http://www.brooklynmuseum.org/opencollection/objects/48833/Textile, Inv. 38.656.

${ }^{64}$ G. LÓPEZ MONTEAGUDO, “La caza en el mosaico romano. Iconografía y simbolismo", Antigüedad y Cristianismo, 8, 1991, pp. 499-500. Las escenas de caza fueron habituales en los trabajos musivos a partir del siglo III como un reflejo de gustos y costumbres.

${ }^{65}$ K.-H. BRUNE, Op. cit., cat.49, pp. 102-103.

${ }^{66}$ L. RODRÍGUEZ PEINADO, “La expresión de la danza en el arte textil del Valle del Nilo", en L. RODRÍ- del Krannert Art Museum de la Universidad de Illinois ${ }^{67}$, donde los cazadores con escudo y banda cruzándoles el pecho, danzan entre arcadas flanqueados en la parte superior e inferior por liebres muy estilizadas al galope minoico (Fig. 6).

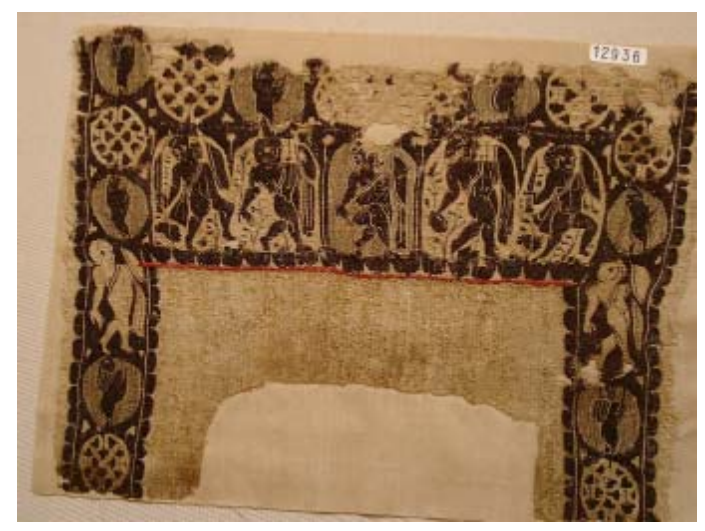

- Fig. 5. Pechera de túnica, Museum Kunst Palast, Düsseldorf, Inv. 12936. Foto: K.-H. BRUNE, Op.cit., cat.49

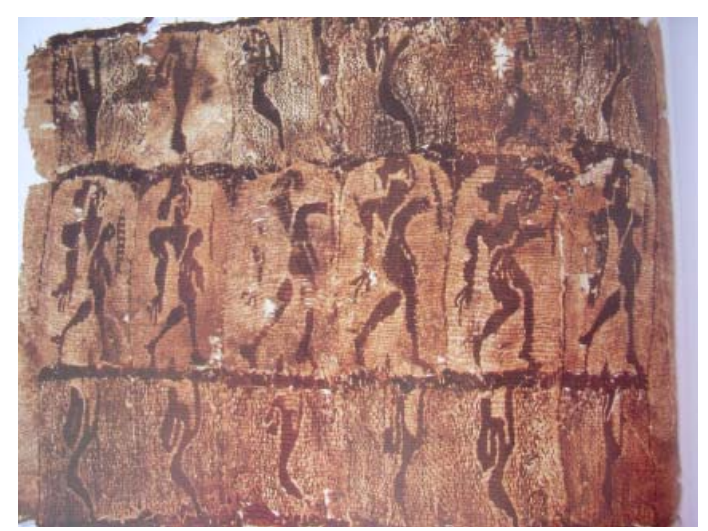

- Fig. 6. Pechera de túnica, Krannert Art Museum, Universidad de Illinois. Foto: E.D. MAGUIRE, Weavings from Roman, Byzantine and Islamic Egypt. The rich life and the dance, UrbanaChampaign, 1999, p. 114

En un orbiculus que forma parte de una colgadura del Museum Kunst Palast de Düsseldorf un cazador en el centro de la

GUEZ PEINADO y A. CABRERA LAFUENTE, La investigación textil... fig. 7, Inv. 13940, p. 85.

${ }^{67}$ E.D. MAGUIRE. Weavings from Roman, Byzantine and Islamic Egypt. The rich life and the dance, UrbanaChampaign, 1999, p. 114. 
composición está rodeado por motivos arbóreos y animales incluidos en círculos entre los que se distinguen dos liebres ${ }^{68}$, pero los otros animales -leones y cabra- aportan a la escena un carácter dionisiaco. En una tabula del mismo museo, alternan incluidos en círculos entrelazados los mismos animales junto a alguna hiena y rodean un jinete que practica esta actividad ${ }^{69}$.

Estos animales no sólo eran valorados como trofeos, también podían verse como una alegoría de los peligros a los que los cazadores tenían que enfrentarse y una metáfora de los escollos a sortear en el camino hacia la otra vida, como podríamos interpretar en el fragmento de banda del Museo Nacional de Hungría, donde la liebre es acosada por un perro y, al galope minoico, gira su cabeza para escapar de su captor ${ }^{70}$. De esta manera se interpreta en el Physiologus, redactado en griego posiblemente en Alejandría entre los siglos I y IV ${ }^{71}$.

La liebre, el león, la pantera y otros animales se presentan junto a bailarines en escenas de danzas dionisiacas donde la vegetación y los animales juegan un importante papel. Por lo general, las escenas de caza y de danza se fusionan porque comparten la misma idea y ambos temas simbolizan la fuerza de vivir, la energía vital y la abundancia de la naturaleza.

Como ya se ha mencionado, la liebre se consagró a Dionisos para evitar la destrucción de los viñedos por el animal. Por esta razón, durante la representación de las danzas extáticas aparece la liebre entre los bailarines y la vegetación, en un esfuerzo

${ }^{68}$ K.-H. BRUNE, Op. cit., cat.12, pp. 42-45.

${ }^{69}$ Ibídem, cat. 96, pp. 154-155. En la Abegg-Stiftung se conserva una tabula de temática similar donde el jinete caza una liebre y alrededor alternan cazadores, animales y plantas en roleos habitados: S. SCHRENK, Textilien des Mittelmeerraumes..., cat. 44, pp. 134-135.

${ }^{70}$ L. TÖRÖK, Coptic Antiquities II. Textiles, "Bibliotheca Archaeologica", 12, Roma, 1993, T. 26, Pl. 1, p. 25.

${ }^{71}$ L. RODRÍGUEZ PEINADO, Los conejos y las liebres..., p. 13.

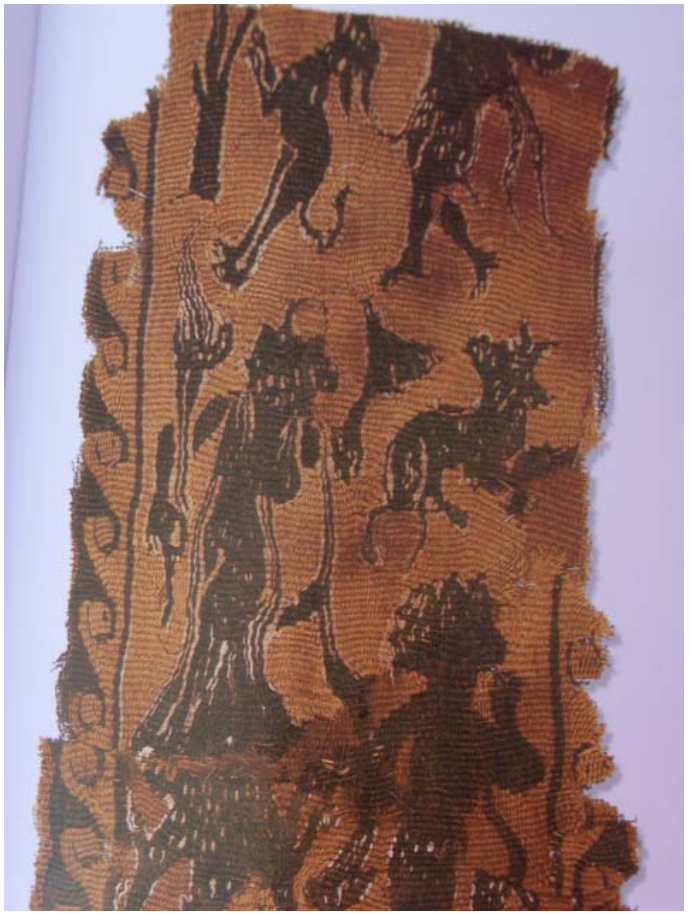

- Fig. 7. Banda, Krannert Art Museum, Universidad de Illinois. Foto: E.D. MAGUIRE, Op.cit., p. $100-101$

por anular su poder destructivo sobre las vides, como se representa en una banda decorativa del Krannert Art Museum de la Universidad de Illinois, donde los bailarines se mueven en un paisaje con animales entre los cuales está la liebre ${ }^{72}$. La decoración de esta banda es muy peculiar porque describe una escena de celebración de ritos dionisiacos nocturna, con una ménade ataviada con una larga túnica y sujetando una antorcha, otra haciendo sonar crótalos, figuras masculinas que danzan y tocan otros instrumentos y animales relacionados con el dios como cabras, felinos y la mencionada liebre lanzada al galope minoico (Fig. 7). En una pechera rematada con clavi de la Abegg-Stiftung de Riggisberg (Berna) también aparece la liebre entre danzantes, pudiendo aludir tanto a ritos dionisiacos como a las danzas propiciatorias para asegurar una abundante caza ${ }^{73}$, mientras en una pie-

${ }^{72}$ E.D. MAGUIRE, Op. cit., pp. 100-101.

${ }^{73}$ S. SCHRENK, Textilien des Mittelmeerraumes..., cat. 69, pp. 202-204. 
za similar de la Fundación Ratti forma parte claramente de un contexto dionisiaco donde bailarines de ambos sexos desarrollan una danza extática ${ }^{74}$. Y queremos destacar por su belleza formal un clavus del Museum Kunst Palast de Düsseldorf, con danzantes desnudos o ataviados con pieles de pantera que se suceden con animales en círculos, entre los que destaca una magnífica liebre, todo ello en un fondo cuajado de pámpanos y racimos (Fig. 8$)^{75}$.

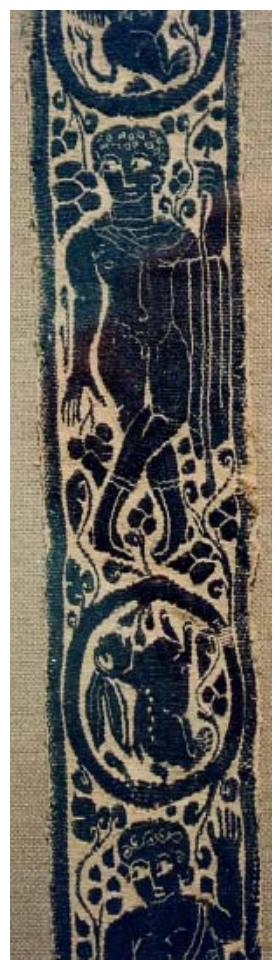

- Fig. 8. Clavus, Museum Kunst Palast, Düsseldorf. Foto: K.-H. BRUNE, Op.cit., cat.77

En el Museu de Montserrat (Barcelona) se conservan cuatro orbiculi fragmentarios, probablemente de una prenda de indumentaria, con un busto central rodeado de cuadrúpedos corriendo en círculo entre los que se distinguen varios lepóridos ${ }^{76}$. Su ico-

${ }^{74}$ Fondazione Antonio Ratti, consultado el 24 de febrero de 2015. URL http://www.fondazioneratti.org/ page/11/coptic-Textiles.

${ }^{75}$ K.-H. BRUNE, Op. cit., cat. 77, pp. 132-133.

${ }^{76}$ Sobre la colección del Museu de Montserrat, véase una síntesis en L.G. TURELL COLL, "Los tejidos nografía es interesante porque los bustos son una manifestación de la tradición retratística romana y al igual que en los sarcófagos podrían identificar a un difunto rodeado de animales benefactores como reflejo de los Campos Elíseos (Fig. 9).

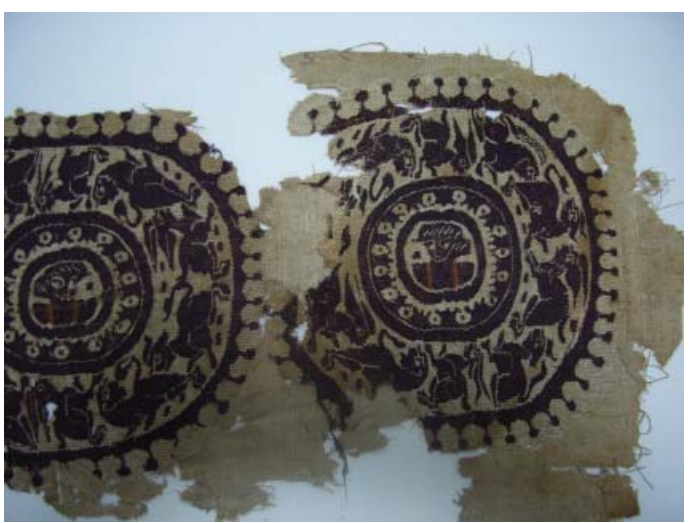

- Fig. 9. Orbiculi, Museu de Montserrat, TCMDM34. Foto de la autora

Con la islamización del territorio egipcio muchos motivos fueron desapareciendo poco a poco y restringiéndose su uso a sectores de la población cada vez más minoritarios, pero la iconografía de la liebre continuó teniendo un importante protagonismo en el arte fatimíi ${ }^{77}$. En los textiles aparece inserta en medallones geométricos inspirados en los roleos o sobre un fondo neutro. Aunque no se puede obviar el peso de la tradición en cuanto a la representación del animal, en estos tejidos se debe interpretar como una declaración de las creencias de los califas fatimíes, seguidores de Alí, marido de la hija del profeta, reencarnado en este animal. Por eso, incluso hoy en día ciertos sectores chiitas no comen su carne por considerar a la liebre un animal sagrado dedicado al yerno de

coptos del Museo de Montserrat. Fuentes documentales y formación de las colecciones" en L. RODRÍGUEZ PEINADO y A. CABRERA LAFUENTE, La investigación textil..., pp. $151-160$.

$77 \mathrm{Su}$ presencia se observa en distintos soportes como cerámica, cristal de roca (abalorio de cristal de roca de la Keir Collection de Londres) o manuscritos miniados (folio de un bestiario procedente de Fustat del Metropolitan Museum of Art de Nueva York). 
Mahoma, intercesor entre Alá y los fieles ${ }^{78}$. En estos tejidos la liebre, animal emblemático y victorioso, se vuelve más estilizada y geometrizada, representándose en general en movimiento, e identificándose por sus largas orejas (Fig. 10).

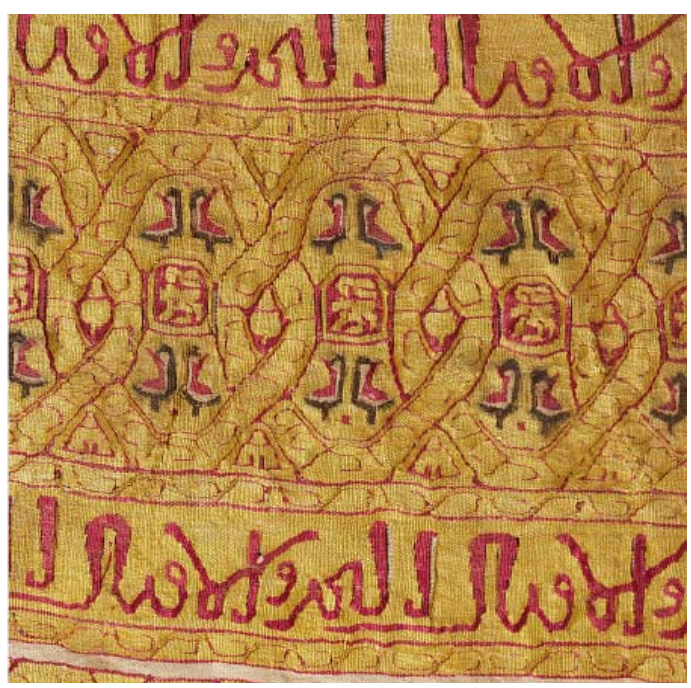

- Fig. 10. Fragmento de tejido fatimí, Royal Ontario Museum. Foto: http://upload.wikimedia. org/wikipedia/commons/thumb/d/d5/Tirazfragment-Fatimid.jpg/915px-Tiraz-fragmentFatimid.jpg

Será en el contexto islámico cuando se represente a la liebre con el hongo funerario en su boca, tanto en cerámica como en tejidos. Aunque, como hemos comentado más arriba, este elemento ya aparece en el arte faraónico $^{79}$, no hemos reparado en su aparición en el arte textil de la Antigüedad Tardía hasta el periodo islámico. Según Zozaya es un tema de origen chino adoptado por el Islam y recuerda la necesidad de traspasar el umbral de la muerte acorde a los mandamientos divinos ${ }^{80}$. Es frecuente en la cerámi-

${ }^{78}$ S. SALADRIGAS CHENG, “Un fragmento de tejido fatimita / A fragment of a Fatimite fabric", Datatèxtil, 16, 2007, pp. 86-87. El Centre de Documentació i Museu Tèxtil de Tarrasa conserva una importante colección de fragmentos textiles donde se representa este motivo.

${ }^{79}$ Cfra. nota 9.

${ }^{80} \mathrm{~J}$. ZOZAYA, "Muerte y transfiguración en la cerámica islámica", Atti del IX Congresso Internazionale sulla ca fatimí, desde donde pasa a al-Andalus ${ }^{81}$, representándose, asimismo, dentro del ámbito andalusí, en la yuba de Oña ${ }^{82}$.

En el sudario de San Lázaro de Autun, adscrito a un tiraz andalusí y fechado a comienzos del siglo XI, se representa la liebre como presa de un águila en los medallones estrellados. En este caso, teniendo en cuenta que el águila es símbolo del poder real, podría tratarse de una alegoría de la sumisión de los súbditos al califa mediante un pasatiempo real como era el tema de la caza, por tanto, su significado en esta pieza varía sustancialmente respecto a tiempos anteriores.

\section{CONCLUSIÓN}

Dentro del periodo en el que hemos enmarcado este estudio, la mayoría de los tejidos donde la liebre adquiere cierto protagonismo se clasifican entre los siglos IV y VI, tiempo en el que el sincretismo religioso en Egipto y las múltiples influencias a que se vio sometida la cultura del territorio da lugar a un arte ciertamente ecléctico donde pervivieron significados arraigados y propios del sustrato tradicional junto a elementos nue-

Ceramica Medievale nel Mediterraneo, (Venecia, 23-27 nov. 2009), Florencia 2012, pp. 458-459.

${ }^{81}$ M. RETUERCE VELASCO, M.Á. HERVÁS HERRERA y A. de JUAN GARCÍA, "La cerámica islámica de Calatrava la Vieja y Alarcos. Nuevos hallazgos", Actas del VIII Congreso Internacional de Cerámica Medieval, Ciudad Real, 2009, tomo II, pp. 745-749. Queremos destacar entre las piezas más significativas los ataifores fatimíes del Museo del Bardo (Túnez) y del Cincinatti Art Museum, decorados en reflejo metálico, y la redoma de las liebres del Museo Arqueológico y Etnológico de Granada con decoración en verde y manganeso y de factura andalusí.

${ }^{82}$ Según M. CASAMAR y J. ZOZAYA, "Apuntes sobre la yuba funeraria de la colegiata de Oña (Burgos)", Boletín de Arqueología Medieval, 5, 1991, p. 49, se representa una sola vez con el hongo funerario, aunque la liebre aparece hasta diez veces en este tejido: M. ALI DE UNZAGA, "Nuevos datos sobre el bordado de Oña: testigo ineludible de la historia, la política y la cultura entre al-Andalus y Castilla", en R. SÁNCHEZ DOMINGO (coord.), Oña. Un milenio. Actas del congreso internacional sobre el monasterio de Oña (1011-2011), Burgos, 2012, p. 565. 
vos que aportaron un valor polisémico a las imágenes, lo que se aprecia cumplidamente en el caso de este animal.

De acuerdo a lo expuesto, en los tejidos donde aparece representada formaron parte de la indumentaria y la ornamentación de espacios civiles y religiosos, y en función de los gustos y creencias de sus propietarios o usos integraría composiciones donde primarían unas intenciones concretas, sin olvidar los gustos que primaban en cada periodo así como los modelos de los que disponían los talleres ${ }^{83}$. En estos casos su significado estaría fundamentalmente relacionado con el contexto general de la composición de la que formaba parte, pero cuando las piezas pasaban a tener su finalidad última como mortaja, su simbolismo funerario ganaría fuerza, porque su imagen se convertía en garante para acometer el viaje al otro mundo cumpliendo la función que en los tiempos faraónicos tuvieron los amuletos de lepóridos.

El apego a la tradición y la pervivencia de diferentes cultos paganos comprensibles por gran parte de la población con independencia de sus creencias religiosas, favoreció el simbolismo con carácter beneficioso de la imagen de la liebre con un sentido general de prosperidad, felicidad, riqueza y protección. Fue un icono con un claro carácter profiláctico y apotropaico que procuraba fertilidad, fortuna y era un claro referente de la renovación cíclica y, por tanto, tenía un poder de regeneración en alusión a la inmortalidad, principio de gran trascendencia para las religiones mistéricas tan arraigadas en las sociedades tardoantiguas, para las que el misterio de la vida se entendía a través de la muerte.

Como ha quedado de manifiesto a partir de los ejemplos elegidos, las liebres no aparecen en la ornamentación textil sólo con valor decorativo, son animales de la buena suerte, por lo que en su significado prima su carácter benefactor, pero este puede experimentar variaciones dependiendo de las escenas de las que forman parte o de la función de los tejidos donde se incluyen. Ya en la época faraónica era el ser bueno que protegía a los muertos en su viaje a la Otra Vida y este significado positivo se mantuvo en el primer cristianismo como imagen de la prudencia, vigilancia y resurrección.

\footnotetext{
${ }^{83}$ Hay que tener en cuenta que cuando se ponía un determinado repertorio de moda parece que podía ser usado por individuos practicantes de diversos ritos, como fue el caso de las denominadas "túnicas de ménades": véase F. PRITCHARD, Clothing culture: dress in Egypt in the first millennium AD, Catálogo de la exposición, Manchester, 2006, pp.73-74.
} 